\title{
ENGINEERING NOTE 3823.130-EN-545
}

\section{B LAYER PIXEL MOVER SUPPORT NORTH A LAYER SIDE ANALYSIS}

\author{
DRAWING No. 3823.130-MB-399167
}

Written by: Tony Levand October 31, 2000

Checked by: Tomperz Date 10-31-00 


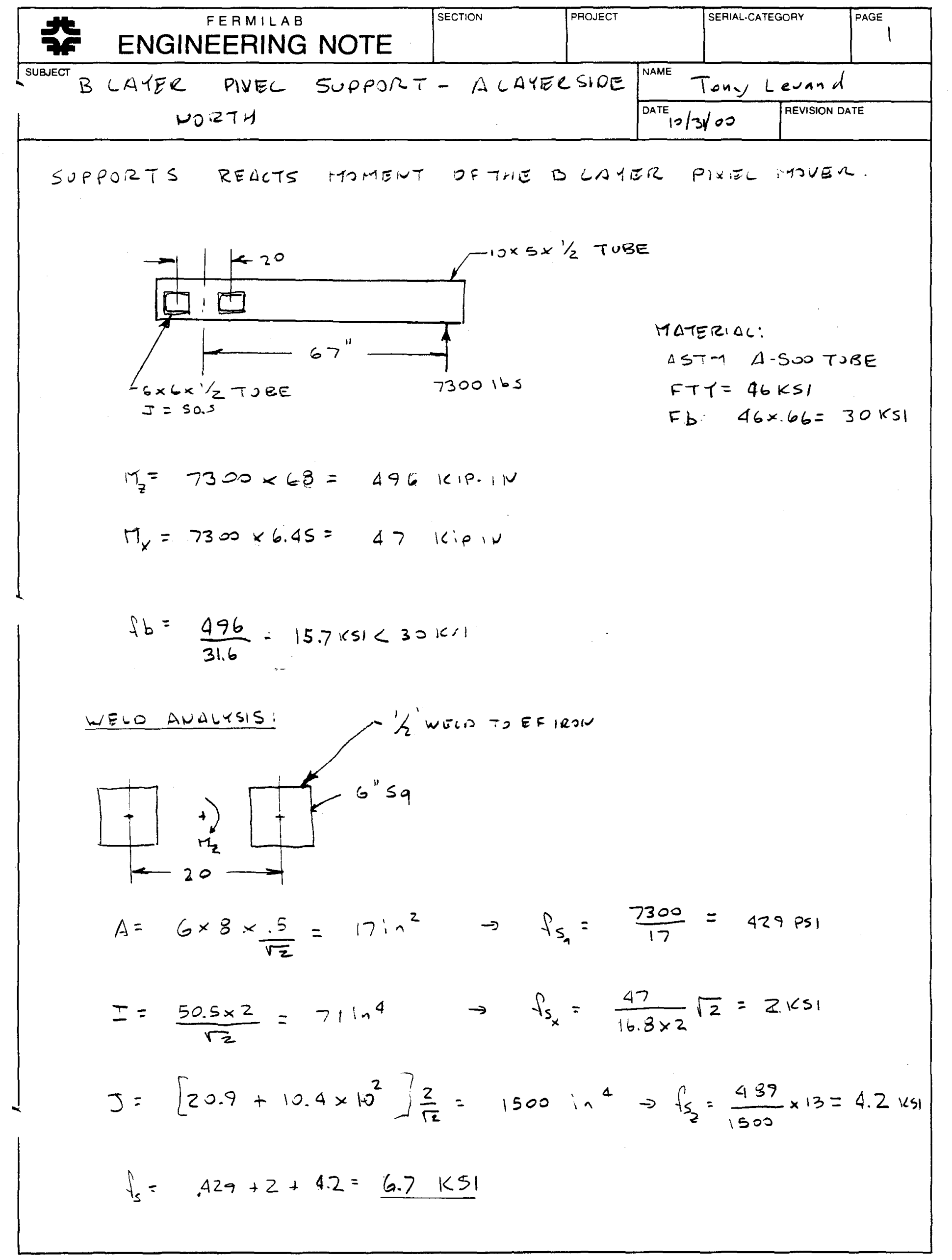




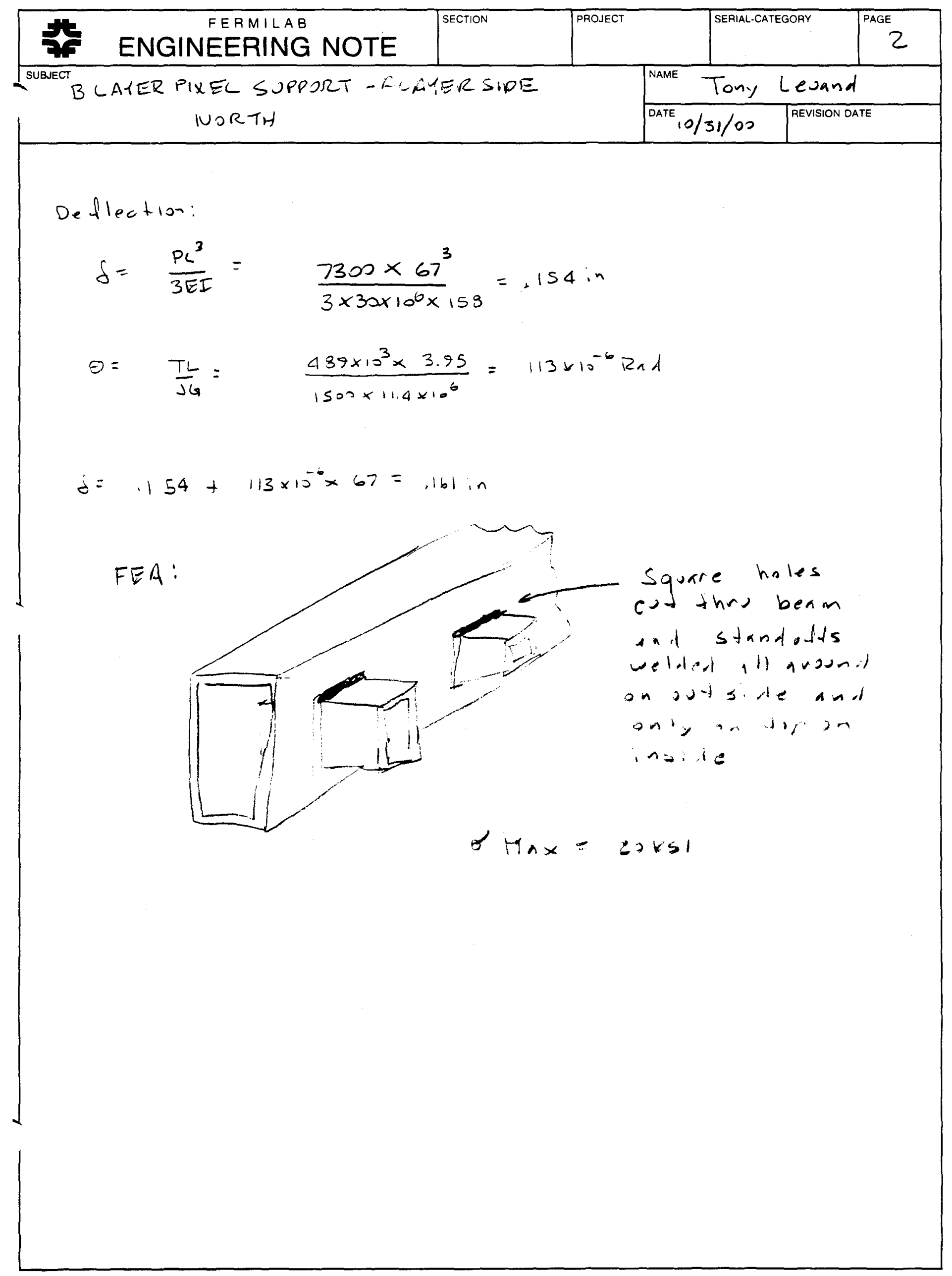


RESULTS: 2- B.C. 1, STRESS_2,LOAD SET 1

STRESS - VON MISES MIN: $1.84 E+02$ MAX: $2.07 E+04$

DEFORMATION: 1 - B.C. 1, DISPLACEMENT_1, LOAD SET 1

DISPLACEMENT - MAG MIN: $0.00 E+00$ MAX: $1.65 E-01$

FRAME OF REF : PART

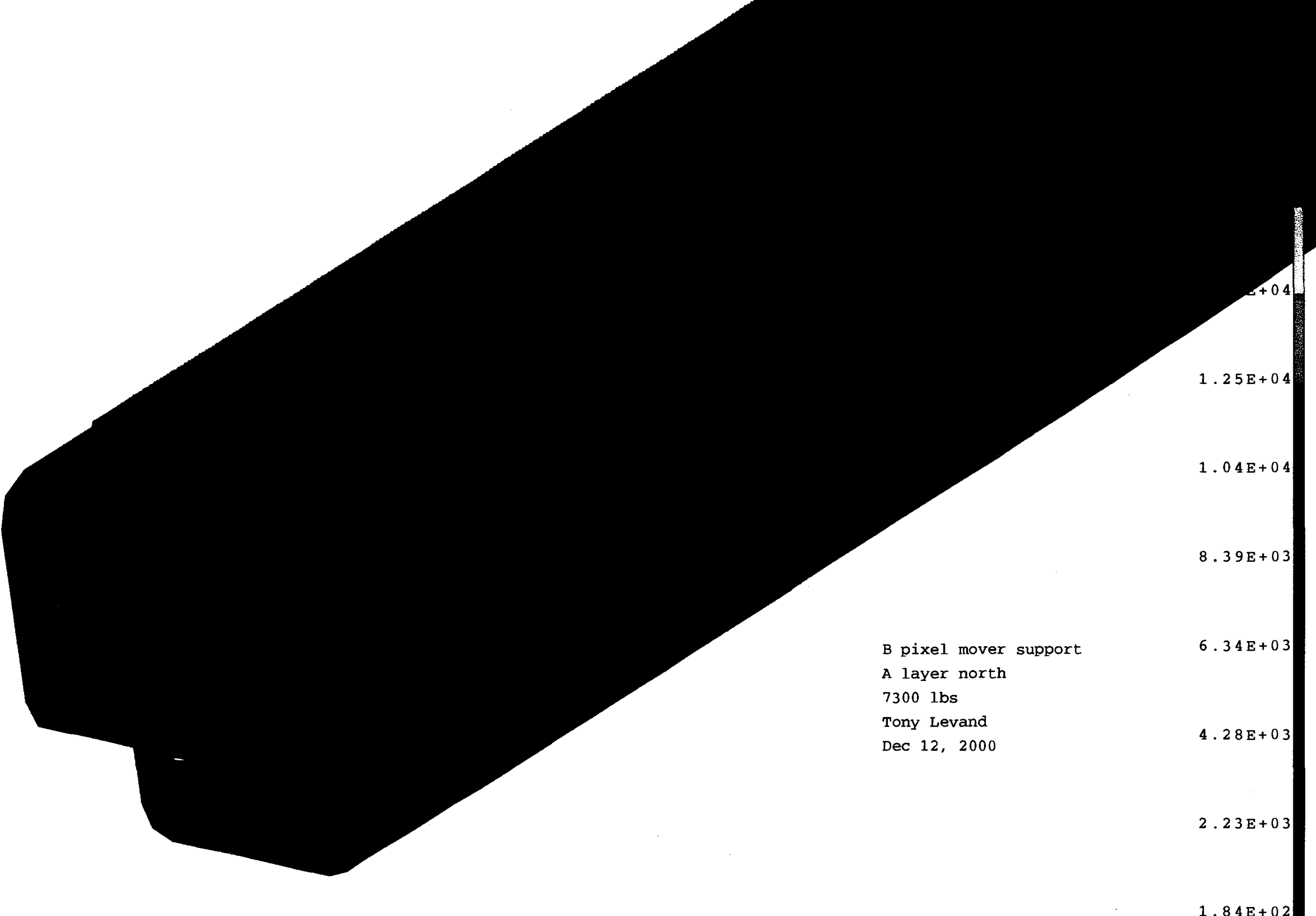


